Available online at https://jurnal.stmikroyal.ac.id/index.php/jurdimas

\title{
IMPLEMENTASI APLIKASI COREL DRAW X4 UNTUK DESAIN GRAFIS BAGI PERANGKAT DESA PINANGGRIPAN KECAMATAN AIR BATU KA- BUPATEN ASAHAN
}

\author{
Dewi Anggraeni \\ Sistem Informasi, STMIK Royal Kisaran \\ email: anggraeni1987@gmail.com
}

\begin{abstract}
The theme of community service activities carried out in Pinanggripan village, Air Batu Subdistrict, Asahan Regency is "Implementation of Corel Draw X4 Application for Graphic Design for Pinanggripan Village Devices, Air Batu District, Asahan Regency". The purpose of the activity is to provide knowledge and skills of village officials in designing graphics using the Corel Draw X4 application. With these knowledge and skills the village device can be creative in designing using the Corel Draw X4 application. The skills of the village apparatus in designing will help balaidesa in making activity banners, brochures, and other designs.
\end{abstract}

Keywords: Graphic Design, Corel Draw X4

Abstrak: Tema kegiatan pengabdian kepada masyarakat yang dilakukan pada desa Pinanggripan, Kecamatan Air Batu, Kabupaten Asahan adalah "Implementasi Aplikasi Corel Draw X4 Untuk Desain Grafis Bagi Perangkat Desa Pinanggripan Kecamatan Air Batu Babupaten Asahan". Tujuan kegiatan dilakukan adalah memberikan pengetahuan dan keterampilan perangkat desa dalam mendesain grafis menggunakan aplikasi Corel Draw X4. Dengan pengetahuan dan keterampilan tersebut perangkat desa dapat berkreasi dalam mendesain menggunakan aplikasi Corel Draw X4. Keterampilan perangkat desa dalam mendesain akan membantu balaidesa dalam pembuatan spanduk kegiatan, brosur, dan rancangan desain lainnya.

Kata kunci: Desain Grafis, Corel Draw X4

\section{PENDAHULUAN}

Balai Desa Pinanggripan merupakan
kantor desa yang menangani
permasalahan yang berhubungan dengan
masyarakat desa. Salah satu bentuk
kegiatan yang dilakukan Balai Desa
Pinanggripan adalah melayani masyara-
kat setempat dalam mengurus segala
sesuatu yang berhubungan dengan identi-
tas dan status masyarakat pada desa ter-
sebut. Misalnya, urusan Kartu Tanda
Penduduk (KTP), Kartu Keluarga (KK),

dan lain sebagainya. Dalam fungsinya sebagai pelayanan masyarakat, Balai Desa Pinanggripan sering melakukan kegiatan penyuluhan dan sosialisasi terhadap masyarakat. Kegiatan-kegitan penyuluhan dan sosialisasi tersebut selalu dibuatkan spanduk sebagai publikasi, ucapan selamat datang, dan lainnya. Spanduk juga selalu dibuat ketika ada tamu-tamu penting yang datang ke Desa Pinanggripan, seperti camat dan pemerintah instansi lainnya. 
Available online at https://jurnal.stmikroyal.ac.id/index.php/jurdimas

Selama ini, untuk membuat spanduk kegiatan, Balai Desa Pinanggripan selalu menempahkan pada pihak luar atau percetakan (digital printing). Masalah yang dihadapi tidak hanya menambah biaya pengeluaran kantor saja, akan tetapi terkadang desain spanduk yang di tempahkan sering terlambat selesainya bahkan sering kesalahan teks pada penulisan dalam spanduk tersebut.

Berdasarkan permasalahan tersebut perkembangan teknologi informasi menjadi acuan oleh Balai Desa Pinanggripan dalam pemanfaatan teknologi informasi untuk perangkat desa khususnya dalam mendesain spanduk untuk kegiatankegiatan yang sering mereka adakan pada Desa Pinaggripan. Untuk itu, dengan adanya peralatan penunjang seperti komputer, staf pegawai beserta kepala desa perlu belajar mendesain sendiri spanduk kegiatan dengan menggunakan aplikasi Corel Draw X4 agar spanduk kegiatan tidak lagi perlu ditempahkan pada pihak luar atau perrcetakan (digital printing).

\section{METODE}

Tahapan atau langkah-langkah yang ditempuh agar kegaitan terlaksana dengan baik dan lancar serta tercapainya tujuan kegiatan pengabdian kepada masyarakat ini adalah:

1. Mempersiapkan materi yang akan diberikan, baik modul, slide presentasi, dan alat peraga lainnya.

2. Memastikan tempat dan fasilitas pendukung seperti in focus, projector, dan lain-lain sudah standby pada saat kegiatan akan dilangsungkan.

3. Sebelum kegiatan dilakukan peserta yang mengikuti kegiatan ini harus sudah memiliki komputer atau laptop sebagai alat praktek.
4. Menjelaskan teori tentang materi aplikasi Corel Draw X4.

5. Praktek langsung pada komputer atau laptop dalam mengimplementasikan objek-objek yang tersedia pada aplikasi Corel Draw X4.

6. Diskusi dan tanya jawab.

Dalam kegiatan ini kepala desa menyediakan tempat selama kegiatan dilangsungkan dan fasilitas-fasilas penunjang yang mereka punya untuk mendukung kegiatan ini berjalan dengan baik dan lancar.

Setelah kegiatan pengabdian kepada masyarakat ini dilakukan, maka langkah selanjutnya adalah Tim pengabdian kepada masyarakat melakukan monitoring selama 3 sampai 4 kali pada Balai Desa Pinanggripan, untuk memastikan perangkat desa sudah benar-benar dapat menggunakan aplikasi Corel Draw X4 secara maksimal atau masih belum. Jika belum, maka Tim akan membantu mengingatkan kembali. Tinjauan ini dilakukan setiap satu kali dalam seminggu pasca kegiatan.

\section{PEMBAHASAN}

1. Workspace

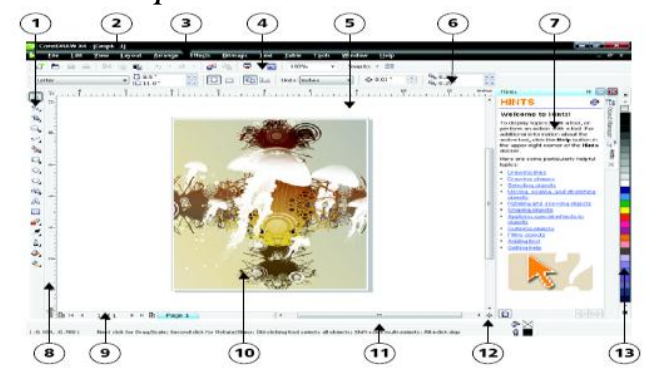

Workspace merupakan area kerja pada corel draw. Di dalam area kerja ini terdapat Toolbox, Title Bar, Menu Bar, Drawing Window, Property Bar, Docker, Ruler, Document Navigator, Drawing Page, Status Bar, dan Color Pallete yang dapat digunakan untuk mendukung kerja 
Available online at https://jurnal.stmikroyal.ac.id/index.php/jurdimas

designer. Masing-masing fitur tersebut dapat di atur sesuai dengan kebutuhan dan keinginan desainer dalam mendesain.

\section{Fungsi Tools Corel Draw X4}

Beberapa fungsi yang ada pada tools Corel Draw X4, yaitu:

a. Pick Tool: Untuk menyeleksi, mengubah ukuran, dan juga memutar arah objek gambar

b. Shape Tool: Menyunting bentuk objek gambar

c. Smudge Brush: Mengubah / mendistorsi keseluruhan gambar dengan menarik garis tepinya.

d. Roughen Brush: Mengubah / mendistorsi keseluruhan outline bentuk gambar dengan menarik garis tepinya.

e. Transform Tool: Mengubah objek gambar menggunakan rotasi (pemutaran posisi) bebas, rotasi sudut, mengubah ukuran dan, dan juga memiringkan bentuk gambar

f. Crop: Menghilangkan bagian yang tidak diinginkan dalam objek.

g. Knife: Mengubah / mendistorsi keseluruhan gambar dengan menarik garis tepinya.

h. Eraser: Menghapus area gambar

3. Menggambar Dengan Corel Draw X4

a. Membuat Rectangular

Pilih Rectangular tool atau tekan F6

Lalu klik (untuk posisi awal) dan drag hingga mendapatkan bentuk kotak yg diinginkan

Lepaskan mouse, hasilnya akan muncul objek kotak

Klik pick tool untuk mengakhiri atau tekan tombol space bar

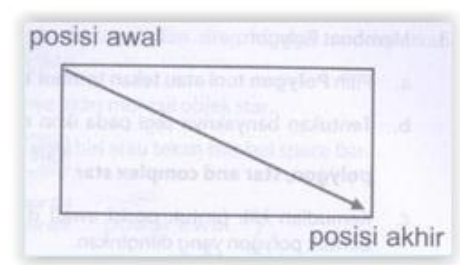

b. Membuat Ellipse

Pilih ellipse tool atau tekan F7

Lalu klik (untuk posisi awal) dan drag hingga mendapatkan bentuk elips yang diinginkan

Lepaskan mouse, hasilnya akan muncul objek elips

Klik pick tool untuk mengakhiri atau tekan space bar

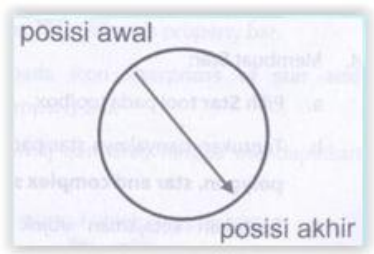

c. Membuat Polygon

Pilih Polygon tool atau tekan tombol $\mathrm{Y}$

Tentukan banyak segi pada icon number of points or sides on polygon, star and complex star pada property bar

$>$ Kemudian klik untuk posisi awal dan drag hingga mendapatkan bentuk polygon yang diinginkan

Lepaskan mouse, hasilnya muncul objek polygon

Klik pick tool untuk mengakhiri atau tekan space bar

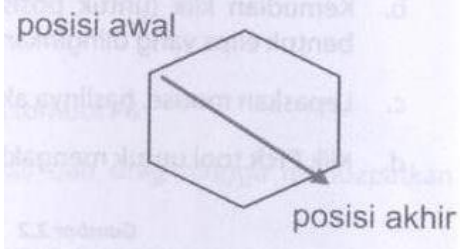

d. Membuat Star

Pilih Star tool pada toolbox 
Available online at https://jurnal.stmikroyal.ac.id/index.php/jurdimas

Tentukan banyaknya star pada icon number of point or sides on polygon, star and complex star pada property bar

Tentukan ketajaman objek pada ikon sharpness of star and complex star pada property bar

Kemudian klik untuk posisi awal dan drag hingga mendapatkan bentuk star yang diinginkan

Lepaskan mouse, hasilnya akan muncuk objek star

Kilik Pick tool untuk mengakhiri atau tekan tombol space bar

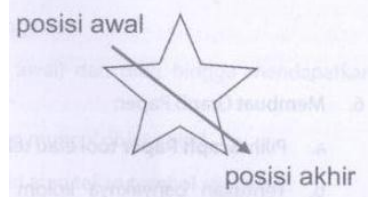

e. Membuat Logo Sederhana

> Langkah Awal tentunya Buka CorelDraw $X 4$, disini saya menggunakan CorelDraw $x 4$

\section{klik File New $(\mathrm{Ctrl}+\mathrm{N})$}

> Setelah itu aktifkan Rectangle Tool Pada Tool Yang Berada Di Sebelah Kiri Lembar Kerja Kemudian buatlah sebuah kotak seperti pada gambar di bawah.

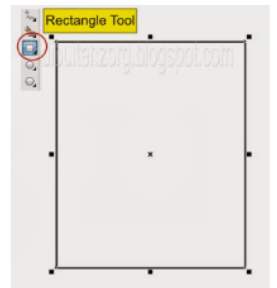

Aktifkan Shape Tool, Atau Dengan Jalan Pintas Yaitu Menekan Tombol F10 Pada Keyboard, lalu tarik salah satu sudut dari kotak tersebut.

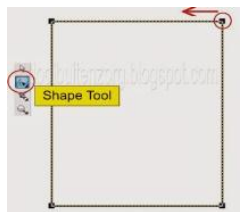

Dan Hasilnya Akan Seperti Gambar Di Bawah.

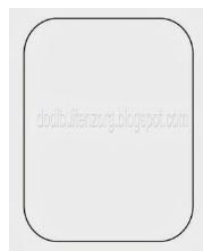

Buat kembali sebuah kotak dan tempatkan Pada Setengah kotak pertama, lihat gambar dibawah

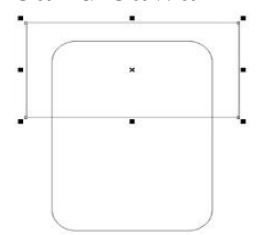

Masih kotak yang baru dibuat tadi, lalu Tekan Tombol SHIFT tahan Lalu Klik Kotak Yang Satunya Lagi Lalu Klik Menu Arrange > Shaping > Trim. Atau Langsung Menekan Trim Pada Property. Maka Kotak Yang Bawah Akan Terpotong Oleh Kotak Di Atasnya, kemudian Hapus kotak yang atas.

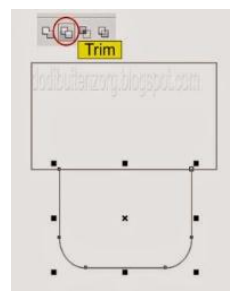

Buatlah Satu (1) buah kotak persegi panjang Lalu ulangi langkah ke 3 - 4, Bila sudah selesai Duplikat Kotak tersebut menjadi 4 Tekan saja tombol Alt + F7 Setelah muncul Kotak Dialog ikuti Seperti Gambar, klik Aplly to Duplicate sehinga Kotak Ada 4, Nantinya Kotak - Kotak Tersebut Akan Kita Jadikan Kaki Dan Tangan.

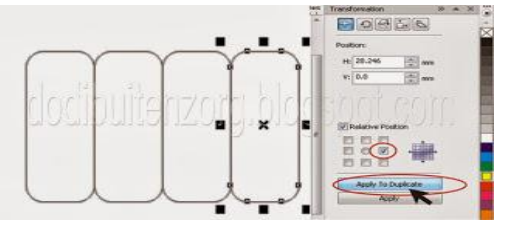

Tempatkan ke 4 kotak tersebut seperti pada gambar dibawah, Kotak Yang 
Available online at https://jurnal.stmikroyal.ac.id/index.php/jurdimas

Dua Sebagai Tangan Dan Yang Lainnya Untuk Kaki

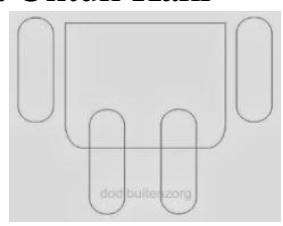

Pilih kedua kotak Bagian kaki Dan Badan Caranya : Klik Kotak Kaki Pertama Sambil Tekan Tombol SHIFT Pada Keyboard Klik Kotak Kaki Ke Dua Sambil Menekan Tombol Shift Klik Kotak Ketiga Yaitu Kotak Badan, lalu klik Menu Arrange > Shaping > Weld. hasilnya akan seperti gambar dibawah.

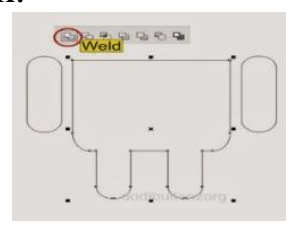

Buatlah sebuah lingkaran dengan menggunakan Ellipse Tool lalu potong lingkaran tersebut hingga menjadi setengah lingkaran (untuk membuat setengah lingkaran langkahnya sama seperti langkah ke 3 - 6). bila sudah tempatkan setengah lingakaran seperti gambar dibawan ini:

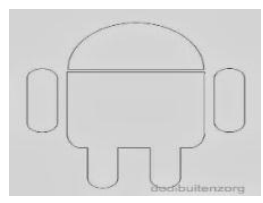

Buat 2 buah kotak seperti gambar dibawah, Kali Ini Ukurannya Diperkecil Kemudian Bulatkan Pada Ujungnya Dengan Menggunakan Shape Tool Seperti Langkah Sebelumnya.

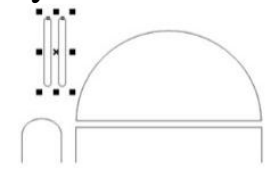

Kemudian Tempatkan Kedua kotak Kecil tersebut seperti gambar dibawah.

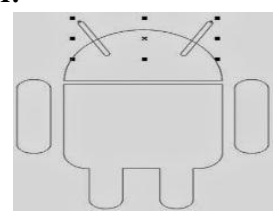

Gabungkan keduanya dengan objek setengah lingkaran Dengan Cara Weld (langkahnya sama seperti langkah ke 9).

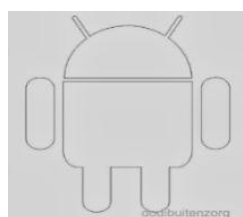

Buat lagi 2 buah lingkaran untuk bagian mata.Lalu Beri Warna Putih. Dan Tempatkan Lingkaran Tersebut Seperti Gambar seperti dibawah ini:

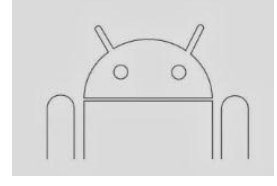

Warnai keseluruhan objek dengan warna hijau Kecuali Bagian Mata Tetap Dengan Warna Putih. Kemudian Hapus Outpennya, (untuk menghilangkan garis tepi pada seluruh objek Seleksi Semua Objek Lalu klik Outline Tool > No Outline, kemudian Seleksi Lagi Dan klik Arrange > grop atau $\mathrm{Ctrl}+\mathrm{G}$ untuk menggabung $\mathrm{Ob}$ jek.

Hasil Akhir
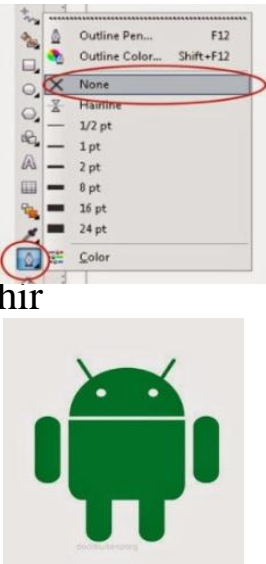
Dibawah ini merupakan dokumentasi kegiatan pelatihan desain grafis menggunakan aplikasi CorelDRaw X4 pada perangkat balai desa Pinanggripan.

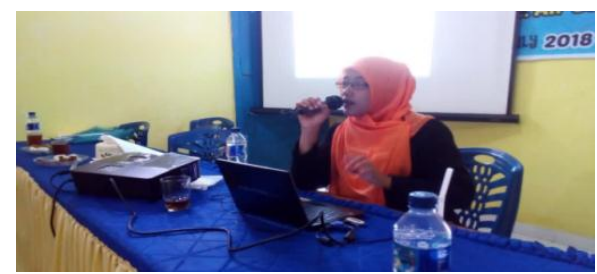

Gambar 1. Penyampaian Materi Oleh Nasumber

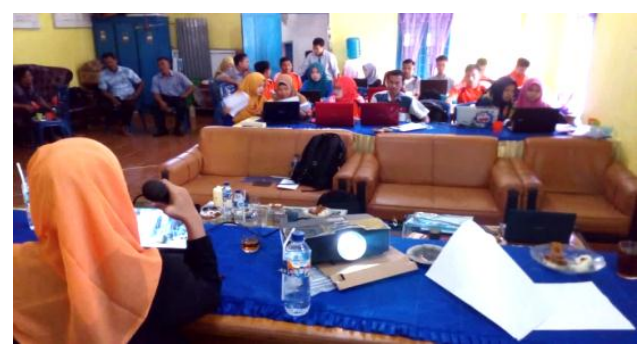

Gambar 2. Penyampaian Materi Oleh Nasumber

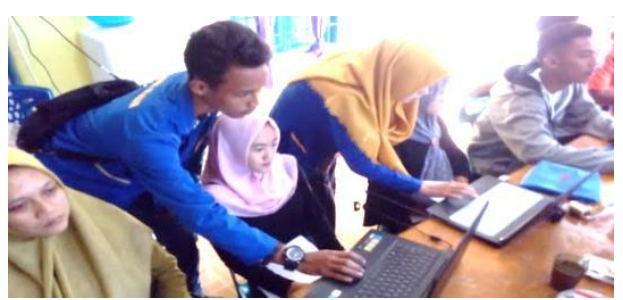

Gambar 7. Proses Praktikum

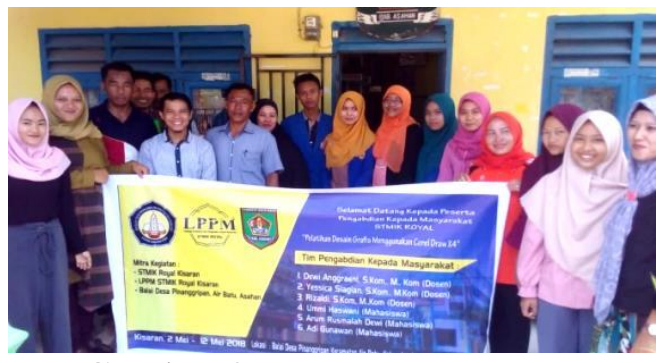

Gambar 8. Foto Bersama Peserta Kegiatan PKM kegiatan (dosen dan mahasiswa STMIK Royal Kisaran) tepat pada sasaran. Materi kegiatan yang diberikan kepada peserta dapat digunakan dan dimanfaatkan untuk mendesain spanduk pada saat adanya kegiatan-kegiatan kedesaan seperti penyuluhan dan sosialisasi.

\section{DAFTAR PUSTAKA}

Rais, R., Afriliana, I., \& Budihartono, E. (2017). Peningkatan Ketrampilan Multimedia CorelDraw Di SMK Assalafiyah kota Tegal. Jurnal Pengabdian Masyarakat Progresif Humanis Brainstorming, 1(1).

Rizaldi, R., Anggraeni, D., \& Syah, A. Z. (2018). TIPS DAN TRIK MEMBANGUN RELATIONSHIP DAN QUERY DALAM DATABASE. Jurdimas (Jurnal Pengabdian Kepada Masyarakat) Royal, 1(2), 45-50.

Sari, M., Rahman, A., \& Yuridka, F. (2017). Pelatihan Design Grafis Coreldraw X4 Sebagai Penunjang Pembelajaran Bagi Guru Pada SMAN 1 Sungai Tabuk. Jurnal Pengabdian Al-Ikhlas Universitas Islam Kalimantan Muhammad Arsyad Al Banjary, 2(1)

\section{SIMPULAN}

Kegiatan pengabdian kepada masyarakat yang dilakukan oleh Tim 